\title{
Experts call for national immunization registry, coordinated schedules
}

$\mathrm{T}$ he Canadian Public Health Association and leading pediatricians and immunologists are calling for a national immunization registry and harmonized vaccination schedules so no one risks missing a vaccine because of where they live.

Both the registry - which would likely consist of a network of linked provincial databases - and harmonized schedules should be part of a renewed national immunization strategy, says Dr. Ian Gemmill, the medical officer of health for Kingston, Frontenac and Lennox \& Addington Public Health in Ontario. Gemmill is one of more than 50 "stakeholders" in public health who are calling for a strengthened national immunization strategy, which would include the registry and coordinated immunization schedules.

Deputy ministers of health across Canada originally approved a national immunization strategy that was funded through a $\$ 45$-million contribution over five years in the 2003 federal budget. A national immunization trust subsequently provided $\$ 300$ million to help the provinces make four additional vaccines - acellular pertussis, meningococcal $\mathrm{C}$ conjugate, pneumococcal conjugate and varicella - available. But many argued that overall progress was limited (www.cmaj.ca/cgi/doi/10.1503 /cmaj.070686).

It's now clear that while access for some vaccines (such as the human papillomavirus vaccine) and vaccine procurement has improved, for some components of the strategy, "it's like the engine got stalled," Gemmill says.

For example, Canada Health Infoway was charged, in the wake of the SARS crisis, with developing a single public health information system for Canada, which would include a national vaccination registry. But the system, called Panorama, has not yet been rolled out in any Canadian jurisdiction.

"It's behind schedule and over budget,

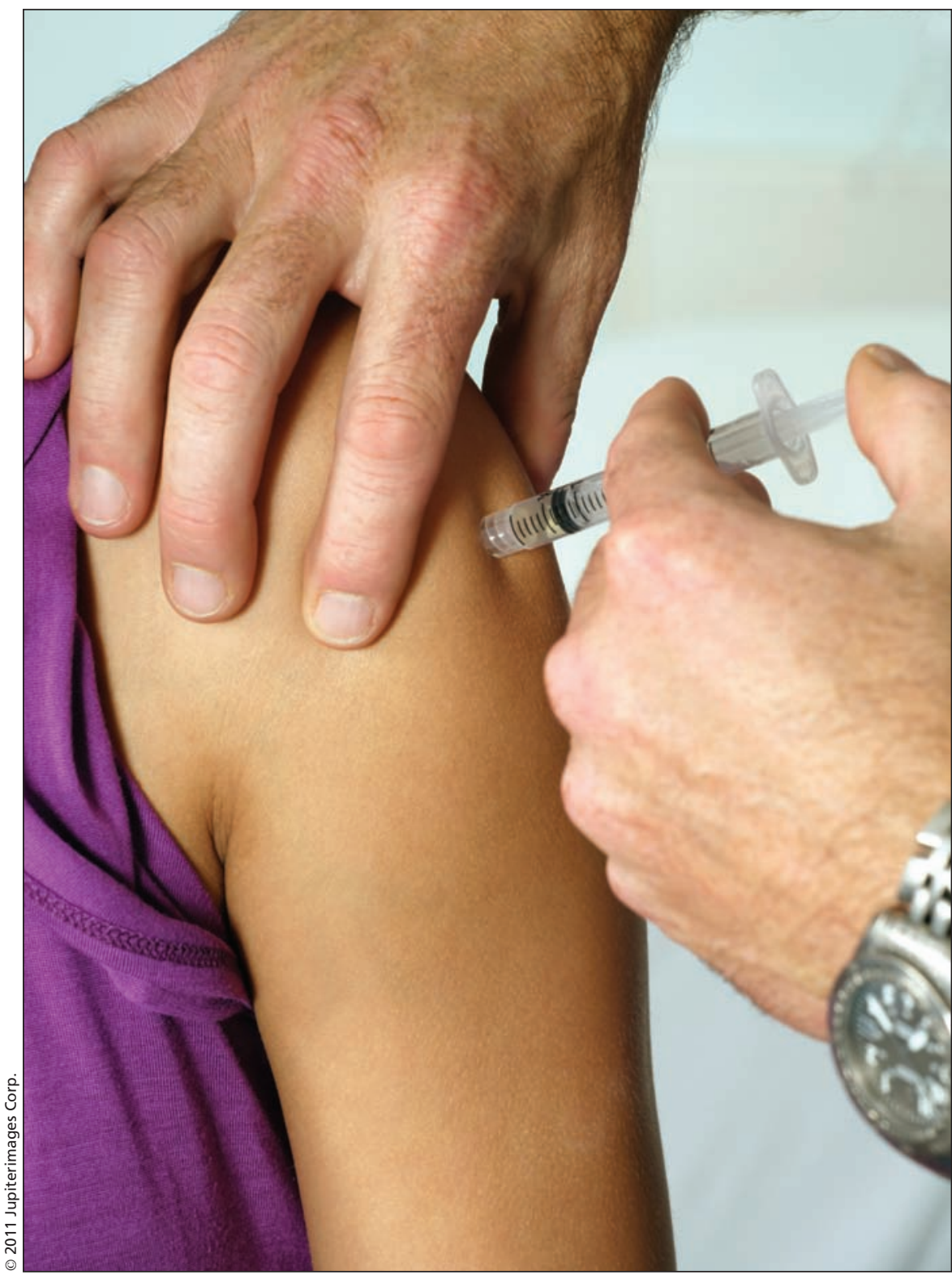

Provinces and territories administer specific vaccines at different ages, so people who move risk missing immunizations.

but it is a potential solution that would allow provinces and territories to run an interconnected network," says Dr. Monika Naus, medical director of immunization programs for the British Columbia Centre for Disease Control.

The physicians are concerned that because there is no national registry, nei- ther health care providers nor patients can track immunization records when people move from one jurisdiction to another.

Ideally, both physicians and patients should be able to access records through a cradle-to-grave electronic database. That would allow them to 
determine what vaccines were missed, which ones require boosters and what new vaccines are available.

"It's a question of equity and transportability," says Dr. Bob Bortolussi, chair of Canadian Paediatric Society's infectious disease and immunization committee and a pediatrician at the IWK Health Centre in Halifax, Nova Scotia.

In addition, because provinces and territories administer specific vaccines at different ages, people who move risk missing immunizations. For example, someone born in Nova Scotia who moves to $\mathrm{BC}$ at age five would likely miss his hepatitis $\mathrm{B}$ vaccination because BC administers it early and Nova Scotia administers it to school-age children.

Registries would also provide better surveillance information, so Canada could evaluate and assess its immunization programs to see what proportion of the population is actually protected against particular diseases, says Naus. "We know that in some countries where vaccination levels have slipped, there have been epidemics or outbreaks of these diseases."

Monitoring uptake on immunizations could also allow public health officials to target education campaigns at regions in which antivaccination advocates have been active, Gemmill says. "If we're not there to provide the infor- mation that people need, and to answer their questions truthfully, then the only source of information those people have is the antivaccination people."

Advocates of a registry and a strengthened strategy say that Canada must overcome barriers to its introduction, including the inability of some jurisdictions to mesh their electronic vaccination databases with those of other provinces or territories.

Another barrier includes the need for revisions in the privacy legislation of some provinces and territories to ensure that vaccination data can be collected and securely held in accessible registries.

The establishment of national standards and schedules within a Canadian Immunization Registries Network is another obstacle.

There is a lack of federal leadership on such issues, say Gemmill and Bortolussi.

"The first and most important (barrier) is political will and money," says Gemmill. "The people who have to fund it need to be convinced. Maybe we in public health need to do a better job of selling the value of registries."

Bortolussi points to Australia as a model of federal leadership. Its central government purchases vaccines for distribution by the states, implements a vaccination schedule and provides funds for states and territories to obtain vaccines listed on the National Immunisation Program. The states then decides whether they want to do so.

"They take [the money], because I think everyone can see there's a benefit to the vaccine," says Bortolussi. "It's for the public good, and having a systematic synchronized immunization program is of benefit to everyone."

By contrast, the Public Health Agency of Canada has a National Advisory Committee on Immunization (NACI), which reviews the merits of every new vaccine, recommends the age at which it should be administered and conducts a cost-benefit analysis. But unlike Australia's federal government, the Canadian government does not offer the provinces and territories $100 \%$ funding for vaccinations, so the provinces and territorites must essentially choose what they want, and can afford, to administer.

Canada lacks the federal leadership required to ensure the advisory committee's recommendations are adopted consistently and that the money exists across the country to pay for them, Bortolussi says. "They need to put some money behind it, so the NACI recommendations can be implemented and take effect." Laura Eggertson, Ottawa, Ont.

CMAJ 2011. DOI:10.1503/cmaj.109-3778 